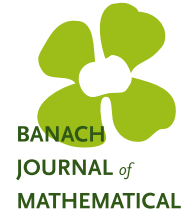

ANALYSIS
Banach J. Math. Anal. 10 (2016), no. 2, 400-414

http://dx.doi.org/10.1215/17358787-3495759

ISSN: $1735-8787$ (electronic)

http://projecteuclid.org/bjma

\title{
NONCONVEX PROXIMAL NORMAL STRUCTURE IN CONVEX METRIC SPACES
}

\author{
MOOSA GABELEH* ${ }^{*}$ and OLIVIER OLELA OTAFUDU \\ To Professor Jamshid Moori on the occasion of his 70th birthday
}

Communicated by W. B. Moors

\begin{abstract}
Given that $A$ and $B$ are two nonempty subsets of the convex metric space $(X, d, \mathcal{W})$, a mapping $T: A \cup B \rightarrow A \cup B$ is noncyclic relatively nonexpansive, provided that $T(A) \subseteq A, T(B) \subseteq B$, and $d(T x, T y) \leq d(x, y)$ for all $(x, y) \in A \times B$. A point $(p, q) \in A \times B$ is called a best proximity pair for the mapping $T$ if $p=T p, q=T q$, and $d(p, q)=\operatorname{dist}(A, B)$. In this work, we study the existence of best proximity pairs for noncyclic relatively nonexpansive mappings by using the notion of nonconvex proximal normal structure. In this way, we generalize a main result of Eldred, Kirk, and Veeramani. We also establish a common best proximity pair theorem for a commuting family of noncyclic relatively nonexpansive mappings in the setting of convex metric spaces, and as an application we conclude a common fixed-point theorem.
\end{abstract}

\section{INTRODUCTION}

Let $(A, B)$ be a pair of subsets of a metric space $(X, d)$. A mapping $T: A \cup$ $B \rightarrow A \cup B$ is said to be noncyclic provided that $T(A) \subseteq A$ and $T(B) \subseteq B$. A point $(p, q) \in A \times B$ is called a best proximity pair if $p=T p, q=T q$, and $d(p, q)=\operatorname{dist}(A, B)$ is satisfied, where $\operatorname{dist}(A, B):=\inf \{d(x, y):(x, y) \in A \times B\}$. Eldred, Kirk, and Veeramani [4] proved the existence of a best proximity pair for a relatively nonexpansive mapping using the geometric notion of proximal normal

Copyright 2016 by the Tusi Mathematical Research Group.

Received May 28, 2015; Accepted Jul. 13, 2015.

${ }^{*}$ Corresponding author.

2010 Mathematics Subject Classification. Primary 46B20; Secondary 47H09.

Keywords. best proximity pair, $T$-regular reflexive pair, nonconvex proximal normal structure, strictly convex metric space. 


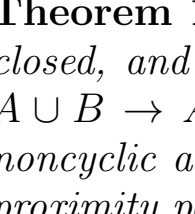

ANALYSIS
Banach J. Math. Anal. 10 (2016), no. 2, 400-414

http://dx.doi.org/10.1215/17358787-3495759

ISSN: $1735-8787$ (electronic)

http://projecteuclid.org/bjma

\title{
NONCONVEX PROXIMAL NORMAL STRUCTURE IN CONVEX METRIC SPACES
}

\author{
MOOSA GABELEH* ${ }^{*}$ and OLIVIER OLELA OTAFUDU \\ To Professor Jamshid Moori on the occasion of his 70th birthday
}

Communicated by W. B. Moors

\begin{abstract}
Given that $A$ and $B$ are two nonempty subsets of the convex metric space $(X, d, \mathcal{W})$, a mapping $T: A \cup B \rightarrow A \cup B$ is noncyclic relatively nonexpansive, provided that $T(A) \subseteq A, T(B) \subseteq B$, and $d(T x, T y) \leq d(x, y)$ for all $(x, y) \in A \times B$. A point $(p, q) \in A \times B$ is called a best proximity pair for the mapping $T$ if $p=T p, q=T q$, and $d(p, q)=\operatorname{dist}(A, B)$. In this work, we study the existence of best proximity pairs for noncyclic relatively nonexpansive mappings by using the notion of nonconvex proximal normal structure. In this way, we generalize a main result of Eldred, Kirk, and Veeramani. We also establish a common best proximity pair theorem for a commuting family of noncyclic relatively nonexpansive mappings in the setting of convex metric spaces, and as an application we conclude a common fixed-point theorem.
\end{abstract}

\section{INTRODUCTION}

Let $(A, B)$ be a pair of subsets of a metric space $(X, d)$. A mapping $T: A \cup$ $B \rightarrow A \cup B$ is said to be noncyclic provided that $T(A) \subseteq A$ and $T(B) \subseteq B$. A point $(p, q) \in A \times B$ is called a best proximity pair if $p=T p, q=T q$, and $d(p, q)=\operatorname{dist}(A, B)$ is satisfied, where $\operatorname{dist}(A, B):=\inf \{d(x, y):(x, y) \in A \times B\}$. Eldred, Kirk, and Veeramani [4] proved the existence of a best proximity pair for a relatively nonexpansive mapping using the geometric notion of proximal normal

Copyright 2016 by the Tusi Mathematical Research Group.

Received May 28, 2015; Accepted Jul. 13, 2015.

${ }^{*}$ Corresponding author.

2010 Mathematics Subject Classification. Primary 46B20; Secondary 47H09.

Keywords. best proximity pair, $T$-regular reflexive pair, nonconvex proximal normal structure, strictly convex metric space. 


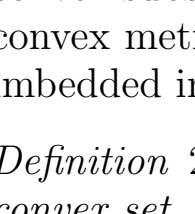

ANALYSIS
Banach J. Math. Anal. 10 (2016), no. 2, 400-414

http://dx.doi.org/10.1215/17358787-3495759

ISSN: $1735-8787$ (electronic)

http://projecteuclid.org/bjma

\title{
NONCONVEX PROXIMAL NORMAL STRUCTURE IN CONVEX METRIC SPACES
}

\author{
MOOSA GABELEH* ${ }^{*}$ and OLIVIER OLELA OTAFUDU \\ To Professor Jamshid Moori on the occasion of his 70th birthday
}

Communicated by W. B. Moors

\begin{abstract}
Given that $A$ and $B$ are two nonempty subsets of the convex metric space $(X, d, \mathcal{W})$, a mapping $T: A \cup B \rightarrow A \cup B$ is noncyclic relatively nonexpansive, provided that $T(A) \subseteq A, T(B) \subseteq B$, and $d(T x, T y) \leq d(x, y)$ for all $(x, y) \in A \times B$. A point $(p, q) \in A \times B$ is called a best proximity pair for the mapping $T$ if $p=T p, q=T q$, and $d(p, q)=\operatorname{dist}(A, B)$. In this work, we study the existence of best proximity pairs for noncyclic relatively nonexpansive mappings by using the notion of nonconvex proximal normal structure. In this way, we generalize a main result of Eldred, Kirk, and Veeramani. We also establish a common best proximity pair theorem for a commuting family of noncyclic relatively nonexpansive mappings in the setting of convex metric spaces, and as an application we conclude a common fixed-point theorem.
\end{abstract}

\section{INTRODUCTION}

Let $(A, B)$ be a pair of subsets of a metric space $(X, d)$. A mapping $T: A \cup$ $B \rightarrow A \cup B$ is said to be noncyclic provided that $T(A) \subseteq A$ and $T(B) \subseteq B$. A point $(p, q) \in A \times B$ is called a best proximity pair if $p=T p, q=T q$, and $d(p, q)=\operatorname{dist}(A, B)$ is satisfied, where $\operatorname{dist}(A, B):=\inf \{d(x, y):(x, y) \in A \times B\}$. Eldred, Kirk, and Veeramani [4] proved the existence of a best proximity pair for a relatively nonexpansive mapping using the geometric notion of proximal normal

Copyright 2016 by the Tusi Mathematical Research Group.

Received May 28, 2015; Accepted Jul. 13, 2015.

${ }^{*}$ Corresponding author.

2010 Mathematics Subject Classification. Primary 46B20; Secondary 47H09.

Keywords. best proximity pair, $T$-regular reflexive pair, nonconvex proximal normal structure, strictly convex metric space. 


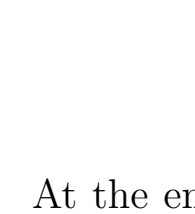

ANALYSIS
Banach J. Math. Anal. 10 (2016), no. 2, 400-414

http://dx.doi.org/10.1215/17358787-3495759

ISSN: $1735-8787$ (electronic)

http://projecteuclid.org/bjma

\title{
NONCONVEX PROXIMAL NORMAL STRUCTURE IN CONVEX METRIC SPACES
}

\author{
MOOSA GABELEH* ${ }^{*}$ and OLIVIER OLELA OTAFUDU \\ To Professor Jamshid Moori on the occasion of his 70th birthday
}

Communicated by W. B. Moors

\begin{abstract}
Given that $A$ and $B$ are two nonempty subsets of the convex metric space $(X, d, \mathcal{W})$, a mapping $T: A \cup B \rightarrow A \cup B$ is noncyclic relatively nonexpansive, provided that $T(A) \subseteq A, T(B) \subseteq B$, and $d(T x, T y) \leq d(x, y)$ for all $(x, y) \in A \times B$. A point $(p, q) \in A \times B$ is called a best proximity pair for the mapping $T$ if $p=T p, q=T q$, and $d(p, q)=\operatorname{dist}(A, B)$. In this work, we study the existence of best proximity pairs for noncyclic relatively nonexpansive mappings by using the notion of nonconvex proximal normal structure. In this way, we generalize a main result of Eldred, Kirk, and Veeramani. We also establish a common best proximity pair theorem for a commuting family of noncyclic relatively nonexpansive mappings in the setting of convex metric spaces, and as an application we conclude a common fixed-point theorem.
\end{abstract}

\section{INTRODUCTION}

Let $(A, B)$ be a pair of subsets of a metric space $(X, d)$. A mapping $T: A \cup$ $B \rightarrow A \cup B$ is said to be noncyclic provided that $T(A) \subseteq A$ and $T(B) \subseteq B$. A point $(p, q) \in A \times B$ is called a best proximity pair if $p=T p, q=T q$, and $d(p, q)=\operatorname{dist}(A, B)$ is satisfied, where $\operatorname{dist}(A, B):=\inf \{d(x, y):(x, y) \in A \times B\}$. Eldred, Kirk, and Veeramani [4] proved the existence of a best proximity pair for a relatively nonexpansive mapping using the geometric notion of proximal normal

Copyright 2016 by the Tusi Mathematical Research Group.

Received May 28, 2015; Accepted Jul. 13, 2015.

${ }^{*}$ Corresponding author.

2010 Mathematics Subject Classification. Primary 46B20; Secondary 47H09.

Keywords. best proximity pair, $T$-regular reflexive pair, nonconvex proximal normal structure, strictly convex metric space. 


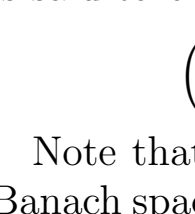

ANALYSIS
Banach J. Math. Anal. 10 (2016), no. 2, 400-414

http://dx.doi.org/10.1215/17358787-3495759

ISSN: $1735-8787$ (electronic)

http://projecteuclid.org/bjma

\title{
NONCONVEX PROXIMAL NORMAL STRUCTURE IN CONVEX METRIC SPACES
}

\author{
MOOSA GABELEH* ${ }^{*}$ and OLIVIER OLELA OTAFUDU \\ To Professor Jamshid Moori on the occasion of his 70th birthday
}

Communicated by W. B. Moors

\begin{abstract}
Given that $A$ and $B$ are two nonempty subsets of the convex metric space $(X, d, \mathcal{W})$, a mapping $T: A \cup B \rightarrow A \cup B$ is noncyclic relatively nonexpansive, provided that $T(A) \subseteq A, T(B) \subseteq B$, and $d(T x, T y) \leq d(x, y)$ for all $(x, y) \in A \times B$. A point $(p, q) \in A \times B$ is called a best proximity pair for the mapping $T$ if $p=T p, q=T q$, and $d(p, q)=\operatorname{dist}(A, B)$. In this work, we study the existence of best proximity pairs for noncyclic relatively nonexpansive mappings by using the notion of nonconvex proximal normal structure. In this way, we generalize a main result of Eldred, Kirk, and Veeramani. We also establish a common best proximity pair theorem for a commuting family of noncyclic relatively nonexpansive mappings in the setting of convex metric spaces, and as an application we conclude a common fixed-point theorem.
\end{abstract}

\section{INTRODUCTION}

Let $(A, B)$ be a pair of subsets of a metric space $(X, d)$. A mapping $T: A \cup$ $B \rightarrow A \cup B$ is said to be noncyclic provided that $T(A) \subseteq A$ and $T(B) \subseteq B$. A point $(p, q) \in A \times B$ is called a best proximity pair if $p=T p, q=T q$, and $d(p, q)=\operatorname{dist}(A, B)$ is satisfied, where $\operatorname{dist}(A, B):=\inf \{d(x, y):(x, y) \in A \times B\}$. Eldred, Kirk, and Veeramani [4] proved the existence of a best proximity pair for a relatively nonexpansive mapping using the geometric notion of proximal normal

Copyright 2016 by the Tusi Mathematical Research Group.

Received May 28, 2015; Accepted Jul. 13, 2015.

${ }^{*}$ Corresponding author.

2010 Mathematics Subject Classification. Primary 46B20; Secondary 47H09.

Keywords. best proximity pair, $T$-regular reflexive pair, nonconvex proximal normal structure, strictly convex metric space. 


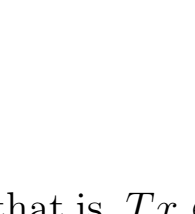

ANALYSIS
Banach J. Math. Anal. 10 (2016), no. 2, 400-414

http://dx.doi.org/10.1215/17358787-3495759

ISSN: $1735-8787$ (electronic)

http://projecteuclid.org/bjma

\title{
NONCONVEX PROXIMAL NORMAL STRUCTURE IN CONVEX METRIC SPACES
}

\author{
MOOSA GABELEH* ${ }^{*}$ and OLIVIER OLELA OTAFUDU \\ To Professor Jamshid Moori on the occasion of his 70th birthday
}

Communicated by W. B. Moors

\begin{abstract}
Given that $A$ and $B$ are two nonempty subsets of the convex metric space $(X, d, \mathcal{W})$, a mapping $T: A \cup B \rightarrow A \cup B$ is noncyclic relatively nonexpansive, provided that $T(A) \subseteq A, T(B) \subseteq B$, and $d(T x, T y) \leq d(x, y)$ for all $(x, y) \in A \times B$. A point $(p, q) \in A \times B$ is called a best proximity pair for the mapping $T$ if $p=T p, q=T q$, and $d(p, q)=\operatorname{dist}(A, B)$. In this work, we study the existence of best proximity pairs for noncyclic relatively nonexpansive mappings by using the notion of nonconvex proximal normal structure. In this way, we generalize a main result of Eldred, Kirk, and Veeramani. We also establish a common best proximity pair theorem for a commuting family of noncyclic relatively nonexpansive mappings in the setting of convex metric spaces, and as an application we conclude a common fixed-point theorem.
\end{abstract}

\section{INTRODUCTION}

Let $(A, B)$ be a pair of subsets of a metric space $(X, d)$. A mapping $T: A \cup$ $B \rightarrow A \cup B$ is said to be noncyclic provided that $T(A) \subseteq A$ and $T(B) \subseteq B$. A point $(p, q) \in A \times B$ is called a best proximity pair if $p=T p, q=T q$, and $d(p, q)=\operatorname{dist}(A, B)$ is satisfied, where $\operatorname{dist}(A, B):=\inf \{d(x, y):(x, y) \in A \times B\}$. Eldred, Kirk, and Veeramani [4] proved the existence of a best proximity pair for a relatively nonexpansive mapping using the geometric notion of proximal normal

Copyright 2016 by the Tusi Mathematical Research Group.

Received May 28, 2015; Accepted Jul. 13, 2015.

${ }^{*}$ Corresponding author.

2010 Mathematics Subject Classification. Primary 46B20; Secondary 47H09.

Keywords. best proximity pair, $T$-regular reflexive pair, nonconvex proximal normal structure, strictly convex metric space. 


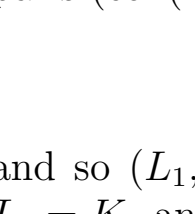

ANALYSIS
Banach J. Math. Anal. 10 (2016), no. 2, 400-414

http://dx.doi.org/10.1215/17358787-3495759

ISSN: $1735-8787$ (electronic)

http://projecteuclid.org/bjma

\title{
NONCONVEX PROXIMAL NORMAL STRUCTURE IN CONVEX METRIC SPACES
}

\author{
MOOSA GABELEH* ${ }^{*}$ and OLIVIER OLELA OTAFUDU \\ To Professor Jamshid Moori on the occasion of his 70th birthday
}

Communicated by W. B. Moors

\begin{abstract}
Given that $A$ and $B$ are two nonempty subsets of the convex metric space $(X, d, \mathcal{W})$, a mapping $T: A \cup B \rightarrow A \cup B$ is noncyclic relatively nonexpansive, provided that $T(A) \subseteq A, T(B) \subseteq B$, and $d(T x, T y) \leq d(x, y)$ for all $(x, y) \in A \times B$. A point $(p, q) \in A \times B$ is called a best proximity pair for the mapping $T$ if $p=T p, q=T q$, and $d(p, q)=\operatorname{dist}(A, B)$. In this work, we study the existence of best proximity pairs for noncyclic relatively nonexpansive mappings by using the notion of nonconvex proximal normal structure. In this way, we generalize a main result of Eldred, Kirk, and Veeramani. We also establish a common best proximity pair theorem for a commuting family of noncyclic relatively nonexpansive mappings in the setting of convex metric spaces, and as an application we conclude a common fixed-point theorem.
\end{abstract}

\section{INTRODUCTION}

Let $(A, B)$ be a pair of subsets of a metric space $(X, d)$. A mapping $T: A \cup$ $B \rightarrow A \cup B$ is said to be noncyclic provided that $T(A) \subseteq A$ and $T(B) \subseteq B$. A point $(p, q) \in A \times B$ is called a best proximity pair if $p=T p, q=T q$, and $d(p, q)=\operatorname{dist}(A, B)$ is satisfied, where $\operatorname{dist}(A, B):=\inf \{d(x, y):(x, y) \in A \times B\}$. Eldred, Kirk, and Veeramani [4] proved the existence of a best proximity pair for a relatively nonexpansive mapping using the geometric notion of proximal normal

Copyright 2016 by the Tusi Mathematical Research Group.

Received May 28, 2015; Accepted Jul. 13, 2015.

${ }^{*}$ Corresponding author.

2010 Mathematics Subject Classification. Primary 46B20; Secondary 47H09.

Keywords. best proximity pair, $T$-regular reflexive pair, nonconvex proximal normal structure, strictly convex metric space. 


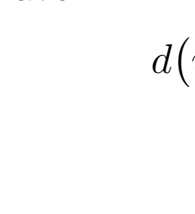

ANALYSIS
Banach J. Math. Anal. 10 (2016), no. 2, 400-414

http://dx.doi.org/10.1215/17358787-3495759

ISSN: $1735-8787$ (electronic)

http://projecteuclid.org/bjma

\title{
NONCONVEX PROXIMAL NORMAL STRUCTURE IN CONVEX METRIC SPACES
}

\author{
MOOSA GABELEH* ${ }^{*}$ and OLIVIER OLELA OTAFUDU \\ To Professor Jamshid Moori on the occasion of his 70th birthday
}

Communicated by W. B. Moors

\begin{abstract}
Given that $A$ and $B$ are two nonempty subsets of the convex metric space $(X, d, \mathcal{W})$, a mapping $T: A \cup B \rightarrow A \cup B$ is noncyclic relatively nonexpansive, provided that $T(A) \subseteq A, T(B) \subseteq B$, and $d(T x, T y) \leq d(x, y)$ for all $(x, y) \in A \times B$. A point $(p, q) \in A \times B$ is called a best proximity pair for the mapping $T$ if $p=T p, q=T q$, and $d(p, q)=\operatorname{dist}(A, B)$. In this work, we study the existence of best proximity pairs for noncyclic relatively nonexpansive mappings by using the notion of nonconvex proximal normal structure. In this way, we generalize a main result of Eldred, Kirk, and Veeramani. We also establish a common best proximity pair theorem for a commuting family of noncyclic relatively nonexpansive mappings in the setting of convex metric spaces, and as an application we conclude a common fixed-point theorem.
\end{abstract}

\section{INTRODUCTION}

Let $(A, B)$ be a pair of subsets of a metric space $(X, d)$. A mapping $T: A \cup$ $B \rightarrow A \cup B$ is said to be noncyclic provided that $T(A) \subseteq A$ and $T(B) \subseteq B$. A point $(p, q) \in A \times B$ is called a best proximity pair if $p=T p, q=T q$, and $d(p, q)=\operatorname{dist}(A, B)$ is satisfied, where $\operatorname{dist}(A, B):=\inf \{d(x, y):(x, y) \in A \times B\}$. Eldred, Kirk, and Veeramani [4] proved the existence of a best proximity pair for a relatively nonexpansive mapping using the geometric notion of proximal normal

Copyright 2016 by the Tusi Mathematical Research Group.

Received May 28, 2015; Accepted Jul. 13, 2015.

${ }^{*}$ Corresponding author.

2010 Mathematics Subject Classification. Primary 46B20; Secondary 47H09.

Keywords. best proximity pair, $T$-regular reflexive pair, nonconvex proximal normal structure, strictly convex metric space. 


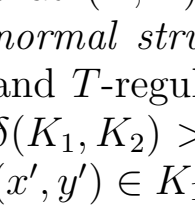

ANALYSIS
Banach J. Math. Anal. 10 (2016), no. 2, 400-414

http://dx.doi.org/10.1215/17358787-3495759

ISSN: $1735-8787$ (electronic)

http://projecteuclid.org/bjma

\title{
NONCONVEX PROXIMAL NORMAL STRUCTURE IN CONVEX METRIC SPACES
}

\author{
MOOSA GABELEH* ${ }^{*}$ and OLIVIER OLELA OTAFUDU \\ To Professor Jamshid Moori on the occasion of his 70th birthday
}

Communicated by W. B. Moors

\begin{abstract}
Given that $A$ and $B$ are two nonempty subsets of the convex metric space $(X, d, \mathcal{W})$, a mapping $T: A \cup B \rightarrow A \cup B$ is noncyclic relatively nonexpansive, provided that $T(A) \subseteq A, T(B) \subseteq B$, and $d(T x, T y) \leq d(x, y)$ for all $(x, y) \in A \times B$. A point $(p, q) \in A \times B$ is called a best proximity pair for the mapping $T$ if $p=T p, q=T q$, and $d(p, q)=\operatorname{dist}(A, B)$. In this work, we study the existence of best proximity pairs for noncyclic relatively nonexpansive mappings by using the notion of nonconvex proximal normal structure. In this way, we generalize a main result of Eldred, Kirk, and Veeramani. We also establish a common best proximity pair theorem for a commuting family of noncyclic relatively nonexpansive mappings in the setting of convex metric spaces, and as an application we conclude a common fixed-point theorem.
\end{abstract}

\section{INTRODUCTION}

Let $(A, B)$ be a pair of subsets of a metric space $(X, d)$. A mapping $T: A \cup$ $B \rightarrow A \cup B$ is said to be noncyclic provided that $T(A) \subseteq A$ and $T(B) \subseteq B$. A point $(p, q) \in A \times B$ is called a best proximity pair if $p=T p, q=T q$, and $d(p, q)=\operatorname{dist}(A, B)$ is satisfied, where $\operatorname{dist}(A, B):=\inf \{d(x, y):(x, y) \in A \times B\}$. Eldred, Kirk, and Veeramani [4] proved the existence of a best proximity pair for a relatively nonexpansive mapping using the geometric notion of proximal normal

Copyright 2016 by the Tusi Mathematical Research Group.

Received May 28, 2015; Accepted Jul. 13, 2015.

${ }^{*}$ Corresponding author.

2010 Mathematics Subject Classification. Primary 46B20; Secondary 47H09.

Keywords. best proximity pair, $T$-regular reflexive pair, nonconvex proximal normal structure, strictly convex metric space. 


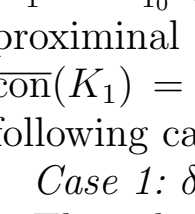

ANALYSIS
Banach J. Math. Anal. 10 (2016), no. 2, 400-414

http://dx.doi.org/10.1215/17358787-3495759

ISSN: $1735-8787$ (electronic)

http://projecteuclid.org/bjma

\title{
NONCONVEX PROXIMAL NORMAL STRUCTURE IN CONVEX METRIC SPACES
}

\author{
MOOSA GABELEH* ${ }^{*}$ and OLIVIER OLELA OTAFUDU \\ To Professor Jamshid Moori on the occasion of his 70th birthday
}

Communicated by W. B. Moors

\begin{abstract}
Given that $A$ and $B$ are two nonempty subsets of the convex metric space $(X, d, \mathcal{W})$, a mapping $T: A \cup B \rightarrow A \cup B$ is noncyclic relatively nonexpansive, provided that $T(A) \subseteq A, T(B) \subseteq B$, and $d(T x, T y) \leq d(x, y)$ for all $(x, y) \in A \times B$. A point $(p, q) \in A \times B$ is called a best proximity pair for the mapping $T$ if $p=T p, q=T q$, and $d(p, q)=\operatorname{dist}(A, B)$. In this work, we study the existence of best proximity pairs for noncyclic relatively nonexpansive mappings by using the notion of nonconvex proximal normal structure. In this way, we generalize a main result of Eldred, Kirk, and Veeramani. We also establish a common best proximity pair theorem for a commuting family of noncyclic relatively nonexpansive mappings in the setting of convex metric spaces, and as an application we conclude a common fixed-point theorem.
\end{abstract}

\section{INTRODUCTION}

Let $(A, B)$ be a pair of subsets of a metric space $(X, d)$. A mapping $T: A \cup$ $B \rightarrow A \cup B$ is said to be noncyclic provided that $T(A) \subseteq A$ and $T(B) \subseteq B$. A point $(p, q) \in A \times B$ is called a best proximity pair if $p=T p, q=T q$, and $d(p, q)=\operatorname{dist}(A, B)$ is satisfied, where $\operatorname{dist}(A, B):=\inf \{d(x, y):(x, y) \in A \times B\}$. Eldred, Kirk, and Veeramani [4] proved the existence of a best proximity pair for a relatively nonexpansive mapping using the geometric notion of proximal normal

Copyright 2016 by the Tusi Mathematical Research Group.

Received May 28, 2015; Accepted Jul. 13, 2015.

${ }^{*}$ Corresponding author.

2010 Mathematics Subject Classification. Primary 46B20; Secondary 47H09.

Keywords. best proximity pair, $T$-regular reflexive pair, nonconvex proximal normal structure, strictly convex metric space. 


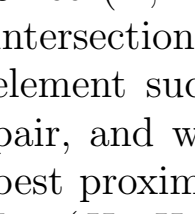

ANALYSIS
Banach J. Math. Anal. 10 (2016), no. 2, 400-414

http://dx.doi.org/10.1215/17358787-3495759

ISSN: $1735-8787$ (electronic)

http://projecteuclid.org/bjma

\title{
NONCONVEX PROXIMAL NORMAL STRUCTURE IN CONVEX METRIC SPACES
}

\author{
MOOSA GABELEH* ${ }^{*}$ and OLIVIER OLELA OTAFUDU \\ To Professor Jamshid Moori on the occasion of his 70th birthday
}

Communicated by W. B. Moors

\begin{abstract}
Given that $A$ and $B$ are two nonempty subsets of the convex metric space $(X, d, \mathcal{W})$, a mapping $T: A \cup B \rightarrow A \cup B$ is noncyclic relatively nonexpansive, provided that $T(A) \subseteq A, T(B) \subseteq B$, and $d(T x, T y) \leq d(x, y)$ for all $(x, y) \in A \times B$. A point $(p, q) \in A \times B$ is called a best proximity pair for the mapping $T$ if $p=T p, q=T q$, and $d(p, q)=\operatorname{dist}(A, B)$. In this work, we study the existence of best proximity pairs for noncyclic relatively nonexpansive mappings by using the notion of nonconvex proximal normal structure. In this way, we generalize a main result of Eldred, Kirk, and Veeramani. We also establish a common best proximity pair theorem for a commuting family of noncyclic relatively nonexpansive mappings in the setting of convex metric spaces, and as an application we conclude a common fixed-point theorem.
\end{abstract}

\section{INTRODUCTION}

Let $(A, B)$ be a pair of subsets of a metric space $(X, d)$. A mapping $T: A \cup$ $B \rightarrow A \cup B$ is said to be noncyclic provided that $T(A) \subseteq A$ and $T(B) \subseteq B$. A point $(p, q) \in A \times B$ is called a best proximity pair if $p=T p, q=T q$, and $d(p, q)=\operatorname{dist}(A, B)$ is satisfied, where $\operatorname{dist}(A, B):=\inf \{d(x, y):(x, y) \in A \times B\}$. Eldred, Kirk, and Veeramani [4] proved the existence of a best proximity pair for a relatively nonexpansive mapping using the geometric notion of proximal normal

Copyright 2016 by the Tusi Mathematical Research Group.

Received May 28, 2015; Accepted Jul. 13, 2015.

${ }^{*}$ Corresponding author.

2010 Mathematics Subject Classification. Primary 46B20; Secondary 47H09.

Keywords. best proximity pair, $T$-regular reflexive pair, nonconvex proximal normal structure, strictly convex metric space. 


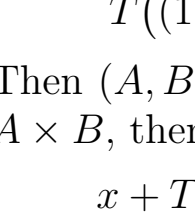

ANALYSIS
Banach J. Math. Anal. 10 (2016), no. 2, 400-414

http://dx.doi.org/10.1215/17358787-3495759

ISSN: $1735-8787$ (electronic)

http://projecteuclid.org/bjma

\title{
NONCONVEX PROXIMAL NORMAL STRUCTURE IN CONVEX METRIC SPACES
}

\author{
MOOSA GABELEH* ${ }^{*}$ and OLIVIER OLELA OTAFUDU \\ To Professor Jamshid Moori on the occasion of his 70th birthday
}

Communicated by W. B. Moors

\begin{abstract}
Given that $A$ and $B$ are two nonempty subsets of the convex metric space $(X, d, \mathcal{W})$, a mapping $T: A \cup B \rightarrow A \cup B$ is noncyclic relatively nonexpansive, provided that $T(A) \subseteq A, T(B) \subseteq B$, and $d(T x, T y) \leq d(x, y)$ for all $(x, y) \in A \times B$. A point $(p, q) \in A \times B$ is called a best proximity pair for the mapping $T$ if $p=T p, q=T q$, and $d(p, q)=\operatorname{dist}(A, B)$. In this work, we study the existence of best proximity pairs for noncyclic relatively nonexpansive mappings by using the notion of nonconvex proximal normal structure. In this way, we generalize a main result of Eldred, Kirk, and Veeramani. We also establish a common best proximity pair theorem for a commuting family of noncyclic relatively nonexpansive mappings in the setting of convex metric spaces, and as an application we conclude a common fixed-point theorem.
\end{abstract}

\section{INTRODUCTION}

Let $(A, B)$ be a pair of subsets of a metric space $(X, d)$. A mapping $T: A \cup$ $B \rightarrow A \cup B$ is said to be noncyclic provided that $T(A) \subseteq A$ and $T(B) \subseteq B$. A point $(p, q) \in A \times B$ is called a best proximity pair if $p=T p, q=T q$, and $d(p, q)=\operatorname{dist}(A, B)$ is satisfied, where $\operatorname{dist}(A, B):=\inf \{d(x, y):(x, y) \in A \times B\}$. Eldred, Kirk, and Veeramani [4] proved the existence of a best proximity pair for a relatively nonexpansive mapping using the geometric notion of proximal normal

Copyright 2016 by the Tusi Mathematical Research Group.

Received May 28, 2015; Accepted Jul. 13, 2015.

${ }^{*}$ Corresponding author.

2010 Mathematics Subject Classification. Primary 46B20; Secondary 47H09.

Keywords. best proximity pair, $T$-regular reflexive pair, nonconvex proximal normal structure, strictly convex metric space. 


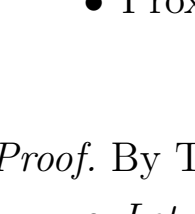

ANALYSIS
Banach J. Math. Anal. 10 (2016), no. 2, 400-414

http://dx.doi.org/10.1215/17358787-3495759

ISSN: $1735-8787$ (electronic)

http://projecteuclid.org/bjma

\title{
NONCONVEX PROXIMAL NORMAL STRUCTURE IN CONVEX METRIC SPACES
}

\author{
MOOSA GABELEH* ${ }^{*}$ and OLIVIER OLELA OTAFUDU \\ To Professor Jamshid Moori on the occasion of his 70th birthday
}

Communicated by W. B. Moors

\begin{abstract}
Given that $A$ and $B$ are two nonempty subsets of the convex metric space $(X, d, \mathcal{W})$, a mapping $T: A \cup B \rightarrow A \cup B$ is noncyclic relatively nonexpansive, provided that $T(A) \subseteq A, T(B) \subseteq B$, and $d(T x, T y) \leq d(x, y)$ for all $(x, y) \in A \times B$. A point $(p, q) \in A \times B$ is called a best proximity pair for the mapping $T$ if $p=T p, q=T q$, and $d(p, q)=\operatorname{dist}(A, B)$. In this work, we study the existence of best proximity pairs for noncyclic relatively nonexpansive mappings by using the notion of nonconvex proximal normal structure. In this way, we generalize a main result of Eldred, Kirk, and Veeramani. We also establish a common best proximity pair theorem for a commuting family of noncyclic relatively nonexpansive mappings in the setting of convex metric spaces, and as an application we conclude a common fixed-point theorem.
\end{abstract}

\section{INTRODUCTION}

Let $(A, B)$ be a pair of subsets of a metric space $(X, d)$. A mapping $T: A \cup$ $B \rightarrow A \cup B$ is said to be noncyclic provided that $T(A) \subseteq A$ and $T(B) \subseteq B$. A point $(p, q) \in A \times B$ is called a best proximity pair if $p=T p, q=T q$, and $d(p, q)=\operatorname{dist}(A, B)$ is satisfied, where $\operatorname{dist}(A, B):=\inf \{d(x, y):(x, y) \in A \times B\}$. Eldred, Kirk, and Veeramani [4] proved the existence of a best proximity pair for a relatively nonexpansive mapping using the geometric notion of proximal normal

Copyright 2016 by the Tusi Mathematical Research Group.

Received May 28, 2015; Accepted Jul. 13, 2015.

${ }^{*}$ Corresponding author.

2010 Mathematics Subject Classification. Primary 46B20; Secondary 47H09.

Keywords. best proximity pair, $T$-regular reflexive pair, nonconvex proximal normal structure, strictly convex metric space. 


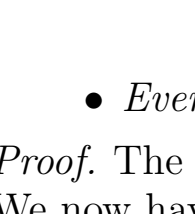

ANALYSIS
Banach J. Math. Anal. 10 (2016), no. 2, 400-414

http://dx.doi.org/10.1215/17358787-3495759

ISSN: $1735-8787$ (electronic)

http://projecteuclid.org/bjma

\title{
NONCONVEX PROXIMAL NORMAL STRUCTURE IN CONVEX METRIC SPACES
}

\author{
MOOSA GABELEH* ${ }^{*}$ and OLIVIER OLELA OTAFUDU \\ To Professor Jamshid Moori on the occasion of his 70th birthday
}

Communicated by W. B. Moors

\begin{abstract}
Given that $A$ and $B$ are two nonempty subsets of the convex metric space $(X, d, \mathcal{W})$, a mapping $T: A \cup B \rightarrow A \cup B$ is noncyclic relatively nonexpansive, provided that $T(A) \subseteq A, T(B) \subseteq B$, and $d(T x, T y) \leq d(x, y)$ for all $(x, y) \in A \times B$. A point $(p, q) \in A \times B$ is called a best proximity pair for the mapping $T$ if $p=T p, q=T q$, and $d(p, q)=\operatorname{dist}(A, B)$. In this work, we study the existence of best proximity pairs for noncyclic relatively nonexpansive mappings by using the notion of nonconvex proximal normal structure. In this way, we generalize a main result of Eldred, Kirk, and Veeramani. We also establish a common best proximity pair theorem for a commuting family of noncyclic relatively nonexpansive mappings in the setting of convex metric spaces, and as an application we conclude a common fixed-point theorem.
\end{abstract}

\section{INTRODUCTION}

Let $(A, B)$ be a pair of subsets of a metric space $(X, d)$. A mapping $T: A \cup$ $B \rightarrow A \cup B$ is said to be noncyclic provided that $T(A) \subseteq A$ and $T(B) \subseteq B$. A point $(p, q) \in A \times B$ is called a best proximity pair if $p=T p, q=T q$, and $d(p, q)=\operatorname{dist}(A, B)$ is satisfied, where $\operatorname{dist}(A, B):=\inf \{d(x, y):(x, y) \in A \times B\}$. Eldred, Kirk, and Veeramani [4] proved the existence of a best proximity pair for a relatively nonexpansive mapping using the geometric notion of proximal normal

Copyright 2016 by the Tusi Mathematical Research Group.

Received May 28, 2015; Accepted Jul. 13, 2015.

${ }^{*}$ Corresponding author.

2010 Mathematics Subject Classification. Primary 46B20; Secondary 47H09.

Keywords. best proximity pair, $T$-regular reflexive pair, nonconvex proximal normal structure, strictly convex metric space. 


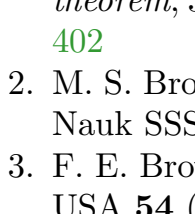

ANALYSIS
Banach J. Math. Anal. 10 (2016), no. 2, 400-414

http://dx.doi.org/10.1215/17358787-3495759

ISSN: $1735-8787$ (electronic)

http://projecteuclid.org/bjma

\title{
NONCONVEX PROXIMAL NORMAL STRUCTURE IN CONVEX METRIC SPACES
}

\author{
MOOSA GABELEH* ${ }^{*}$ and OLIVIER OLELA OTAFUDU \\ To Professor Jamshid Moori on the occasion of his 70th birthday
}

Communicated by W. B. Moors

\begin{abstract}
Given that $A$ and $B$ are two nonempty subsets of the convex metric space $(X, d, \mathcal{W})$, a mapping $T: A \cup B \rightarrow A \cup B$ is noncyclic relatively nonexpansive, provided that $T(A) \subseteq A, T(B) \subseteq B$, and $d(T x, T y) \leq d(x, y)$ for all $(x, y) \in A \times B$. A point $(p, q) \in A \times B$ is called a best proximity pair for the mapping $T$ if $p=T p, q=T q$, and $d(p, q)=\operatorname{dist}(A, B)$. In this work, we study the existence of best proximity pairs for noncyclic relatively nonexpansive mappings by using the notion of nonconvex proximal normal structure. In this way, we generalize a main result of Eldred, Kirk, and Veeramani. We also establish a common best proximity pair theorem for a commuting family of noncyclic relatively nonexpansive mappings in the setting of convex metric spaces, and as an application we conclude a common fixed-point theorem.
\end{abstract}

\section{INTRODUCTION}

Let $(A, B)$ be a pair of subsets of a metric space $(X, d)$. A mapping $T: A \cup$ $B \rightarrow A \cup B$ is said to be noncyclic provided that $T(A) \subseteq A$ and $T(B) \subseteq B$. A point $(p, q) \in A \times B$ is called a best proximity pair if $p=T p, q=T q$, and $d(p, q)=\operatorname{dist}(A, B)$ is satisfied, where $\operatorname{dist}(A, B):=\inf \{d(x, y):(x, y) \in A \times B\}$. Eldred, Kirk, and Veeramani [4] proved the existence of a best proximity pair for a relatively nonexpansive mapping using the geometric notion of proximal normal

Copyright 2016 by the Tusi Mathematical Research Group.

Received May 28, 2015; Accepted Jul. 13, 2015.

${ }^{*}$ Corresponding author.

2010 Mathematics Subject Classification. Primary 46B20; Secondary 47H09.

Keywords. best proximity pair, $T$-regular reflexive pair, nonconvex proximal normal structure, strictly convex metric space. 